\title{
Analysis of Metal Copper Concentration at Candy using Atomic Absorption Spectrophotometry (AAS)
}

\author{
Eny Rahmawati ${ }^{1}$, Diana Candra Dewi ${ }^{1}$, A. Ghanaim Fasya ${ }^{1}$, Begum Fauziyah ${ }^{2}$ \\ ${ }^{1}$ Jurusan Kimia, Fakultas Sains dan Teknologi, Universitas Islam Negeri Maulana Malik Ibrahim Malang \\ ${ }^{2}$ Jurusan Farmasi, Fakultas Sains dan Teknologi, Universitas Islam Negeri Maulana Malik Ibrahim Malang \\ Email: dayanasidi@yahoo.com
}

\begin{abstract}
Candy sold in the market could be containing a heavy metals like copper. In this study, candy was destructed with $\mathrm{HNO} 3$, HNO3/H2SO4 (3:1) dan $\mathrm{HNO} / \mathrm{H} 2 \mathrm{SO} 4 / \mathrm{H} 2 \mathrm{O} 2$ (6:2:1) to know the best matter oxidixer for copper. Then, evaluated the levels of copper using Atomic Absorption Spectrophotometer (AAS). The one way anove result with $\mathrm{F}$ test showed that the best oxidizer for copper in candy is $\mathrm{HNO} / \mathrm{H} 2 \mathrm{SO} 4$. The average concentration of Copper in candy coded A, B, C, D, and E were $1.72 \mathrm{mg} / \mathrm{Kg} ; 1.69 \mathrm{mg} / \mathrm{Kg} ; 1.57 \mathrm{mg} / \mathrm{Kg} ; 1.71$ $\mathrm{mg} / \mathrm{Kg}$; and $1.69 \mathrm{mg} / \mathrm{Kg}$ respectively. The content of copper in candies were the under daily dietary recommended limit based on SNI regulation.
\end{abstract}

Key Words: Atomic Absorption Spectrophotometry, candy, matter oxidizer, time stability, wet destruction

\section{Abstrak}

Permen yang dijual di pasaran diduga mengandung sejumlah logam berat misalnya logam tembaga. Dalam penelitian ini, sampel permen didestruksi dengan $\mathrm{HNO}_{3}, \mathrm{HNO}_{3} / \mathrm{H}_{2} \mathrm{SO}_{4}$ (3:1) dan $\mathrm{HNO}_{3} / \mathrm{H}_{2} \mathrm{SO}_{4} / \mathrm{H}_{2} \mathrm{O}_{2}$ (6:2:1) untuk mengetahui zat pengoksidasi terbaik logam tembaga pada permen. Selanjutnya dilakukan pengukuran kadar logam tembaga dengan Spektrofotometer Serapan Atom (SSA). Hasil analisis uji one way anove dengan uji $\mathrm{F}$ menunjukkan bahwa zat pengoksidasi terbaik logam tembaga dalam sampel permen adalah $\mathrm{HNO}_{3} / \mathrm{H}_{2} \mathrm{SO}_{4}$. Sementara itu, perolehan kadar logam tembaga pada permen dengan label A, B, C, D, dan E berturut-turut sebesar 1,72 mg/Kg; $1,69 \mathrm{mg} / \mathrm{Kg} ; 1,57 \mathrm{mg} / \mathrm{Kg} ; 1,71 \mathrm{mg} / \mathrm{Kg}$; dan 1,69 mg/Kg. Dengan demikian, kadar logam tembaga pada permen yang dijual di pasaran masih berada dalam batas aman konsumsi yang ditetapkan oleh SNI.

Kata Kunci: Spektrofotometri Serapan Atom, permen, oksidator, waktu stabilitas, destruksi basah

\section{PENDAHULUAN}

Permen adalah salah satu jenis makanan yang disukai oleh semua kalangan baik anak-anak maupun orang dewasa. Permen yang diperjualbelikan di pasaran diindikasikan mengandung logam berat seperti tembaga. Di Nigeria, kadar logam tembaga pada permen dan cokelat import di Nigeria berkisar dari 3,0-4,2 mg/g (Ochu, 2012). Sementara itu, di Turki, kadar logam tembaga pada chewing gums dan permen berkisar dari 0,219 - 2,455 $\mu \mathrm{g} / \mathrm{g}$ (Duran, 2009). Sedangkan kadar logam tembaga yang dijual disekitaran Sekolah Dasar di Korea Selatan sebesar $0,7 \mathrm{mg} / \mathrm{Kg}$ (KiChoel, 2008).

Kandungan tembaga pada permen bersumber dari bahan baku berupa gula dan air. Kadar logam tembaga pada gula pasir sebesar 0,9375 mg/Kg (Annisa, 2012). Sedangkan kandungan logam tembaga pada air sebesar 0,01 mg/L (Prihatiningsih, 2009). Darmono (1995) juga menyebutkan bahwa proses pembuatan permen menggunakan alat-alat industri yang terbuat dari logam juga berkontribusi terhadap terjadinya migrasi logam ke dalam bahan pangan.

Sampel permen dipreparasi dengan destruksi basah menggunakan zat pengoksidasi $\mathrm{HNO}_{3}, \quad \mathrm{HNO}_{3} / \mathrm{H}_{2} \mathrm{SO}_{4}$ (3:1) dan $\quad \mathrm{HNO}_{3} / \mathrm{H}_{2} \mathrm{SO}_{4} / \mathrm{H}_{2} \mathrm{O}_{2} \quad$ (6:3:1). Kristianingrum (2012) mengatakan bahwa untuk mendapatkan kadar logam yang maksimal, pemilihan jenis asam pengoksidasi terbaik sangat penting. 
Metode SSA merupakan metode yang tepat untuk pengukuran kadar logam. Kelebihan metode ini yaitu sensitif, akurat, analisisnya teliti dan cepat, pengerjaannya relatif sederhana dan tidak perlu dilakukan pemisahan unsur logam dalam pelaksanaannya.

\section{METODE PENELITIAN Alat dan Bahan}

Alat yang digunakan dalam penelitian ini adalah seperangkat instrumen Spektrometer Serapan Atom (SSA) merek Varian spectra AA 240, peralatan gelas laboratorium, neraca analitik merk Kern, hot plate dan magnetic stirrer.

Bahan yang digunakan dalam penelitian ini adalah larutan standar $\mathrm{Cu}\left(\mathrm{NO}_{3}\right)_{2}$ E Merck, $\mathrm{HNO}_{3}$ p.a, $\mathrm{H}_{2} \mathrm{SO}_{4}$ p.a, $\mathrm{H}_{2} \mathrm{O}_{2}$ p.a, dan aquadestila.

\section{PROSEDUR PENELITIAN Pemilihan Sampel}

Lima sampel permen dengan merek berbeda di beli di supermarket yang berbeda di Kota Malang. Masing-masing produk memiliki kode produksi dan masa kadaluarsa yang sama.

\section{Pengaturan Alat Spektroskopi Serapan Atom Logam Tembaga}

Pengaturan alat Spektroskopi Serapan Atom varian Spectra AS 240 meliputi panjang gelombang $324,8 \mathrm{~nm}$, laju alir asetilen pada $2,0 \mathrm{~L} /$ menit, laju udara pada 10,0 L/menit, lebar celah menggunakan variasi $0,5 \mathrm{~nm}$ dan $1,0 \mathrm{~nm}$, kuat arus $\mathrm{HCl} 10,0 \mu \mathrm{A}$, tinggi burner 2,0 mm (Varian, 2010).

\section{Pembuatan Kurva Baku Tembaga}

Dibuat sederetan larutan standar $\mathrm{Cu}$ 0,00 mg/L, 0,02 mg/L, 0,04 mg/L, 0,06 $\mathrm{mg} / \mathrm{L}, \quad 0,08 \mathrm{mg} / \mathrm{L}$ dan $0,1 \mathrm{mg} / \mathrm{L}$ dengan pengencer $\mathrm{HNO}_{3}$ 0,5 $\mathrm{M}$ ke dalam labu ukur $50 \mathrm{~mL}$ lalu diencerkan sampai tanda batas. Larutan standar dianalisis dengan Spektrofotometer Serapan Atom (SSA) merk Varian Spectra AA 240 pada kondisi optimum sehingga diperoleh data absorbansi.

Penentuan Zat pengoksidasi Terbaik Kadar Tembaga Pada Permen Menggunakan Destruksi Basah

Sebanyak 1 gram sampel permen yang telah dihaluskan ditimbang menggunakan neraca analitik. Sampel diletakkan ke dalam beaker glass $100 \mathrm{~mL}$ untuk dilakukan destruksi basah menggunakan larutan $\mathrm{HNO}_{3}$ p.a sebanyak $30 \mathrm{~mL}$ dan zat pengoksidasi yang lain (sesuai dengan tabel 3.1) ditambahkan ke dalam beaker glass. Lalu dipanaskan di atas hot plate pada suhu $100{ }^{\circ} \mathrm{C}$ selama 3 jam sampai larutan berwarna jernih. Apabila larutan masih berwarna keruh maka ditambahkan $\mathrm{HNO}_{3}$ p.a dan zat pengoksidasi yang lain (sesuai dengan tabel 3.1) sebanyak $30 \mathrm{~mL}$. Larutan hasil destruksi didinginkan dan dimasukkan ke dalam labu ukur $10 \mathrm{~mL}$ lalu ditandabataskan dengan $\mathrm{HNO}_{3} \quad 0,5 \quad \mathrm{M}$. Larutan sampel yang dihasilkan disaring dengan kertas Whatmann 42 dan diukur absorbansinya pada panjang gelombang $324,8 \mathrm{~nm}$. Pengukuran dilakukan sebanyak 3 kali ulangan.

Tabel 1 Variasi zat pengoksidasi

\begin{tabular}{|c|l|c|}
\hline $\begin{array}{c}\text { Berat } \\
\text { Sampel } \\
(\mathrm{gr})\end{array}$ & Zat pengoksidasi & $\begin{array}{c}\text { Volume } \\
(\mathrm{mL})\end{array}$ \\
\hline 1 & Larutan $\mathrm{HNO}_{3}$ & 30 \\
\hline 1 & $\begin{array}{l}\text { Larutan } \mathrm{HNO}_{3} / \mathrm{H}_{2} \mathrm{SO}_{4} \\
3: 1(22,5 \mathrm{ml} / 7,5 \mathrm{~mL})\end{array}$ & 30 \\
\hline 1 & $\begin{array}{l}\text { Larutan } \mathrm{SNO}_{3} / \mathrm{H}_{2} \mathrm{SO}_{4} / \mathrm{H}_{2} \mathrm{O}_{2} \\
6: 2: 1(20 \mathrm{~mL} / 6,7 \mathrm{~mL} /\end{array}$ & 30 \\
& \begin{tabular}{l}
$6,3 \mathrm{~mL})$ \\
\hline
\end{tabular} \\
\hline
\end{tabular}

\section{Penentuan Kadar Logam Tembaga Pada Permen dengan Zat pengoksidasi Terbaik}

Preparasi sampel untuk penelitian ini diambil sebanyak 1 gram masingmasing sampel (A, B, C, D dan E) 
kemudian ditambahkan zat pengoksidasi terbaik. Sampel dipanaskan di atas hot plate pada suhu $100{ }^{\circ} \mathrm{C}$ selama 3 jam sampai larutan berwarna jernih. Larutan hasil destruksi didinginkan dan dimasukkan ke dalam labu ukur $50 \mathrm{~mL}$ lalu ditandabataskan dengan $\mathrm{HNO}_{3} \quad 0,5 \quad \mathrm{M}$. Larutan disaring dengan kertas Whatmann 42 dan diukur absorbansinya pada panjang gelombang 324,8 $\mathrm{nm}$ dan dilakukan 3 kali pengulangan

\section{HASIL DAN PEMBAHASAN}

Sampel permen dipreparasi dengan destruksi basah menggunakan zat pengoksidasi berupa $\mathrm{HNO}_{3}, \mathrm{HNO}_{3} / \mathrm{H}_{2} \mathrm{SO}_{4}$ (3:1) dan $\mathrm{HNO}_{3} / \mathrm{H}_{2} \mathrm{SO}_{4} / \mathrm{H}_{2} \mathrm{O}_{2} \quad(6: 2: 1)$.. Perlakukan ini bertujuan untuk memutuskan ikatan antara logam dengan senyawa organik yang terikat dengannya. Metode ini digunakan karena pengerjaannya lebih sederhana, oksidasi terjadi secara kontinyu dan cepat serta unsur-unsur yang diperoleh mudah larut sehingga dapat ditentukan dengan metode analisa tertentu. Metode destruksi basah dilakukan dengan bantuan panas yang bertujuan untuk mempercepat proses oksidasi atau perombakan senyawasenyawa organik. Selama proses destruksi berlangsung, terjadi pemutusan ikatan antara antara logam dengan senyawa organik yang ditandai dengan terbentuknya warna cokelat kemerah-merahan yang merupakan gas $\mathrm{NO}_{2}$. Proses tersebut digambarkan dengan reaksi berikut:

$$
\begin{aligned}
& \mathrm{M}-\left(\mathrm{CH}_{2} \mathrm{O}\right)_{\mathrm{x}}+\mathrm{HNO}_{3} \rightarrow \mathrm{M}-\left(\mathrm{NO}_{3}\right) \mathrm{x}_{(\mathrm{aq})} \\
& \mathrm{CO}_{2(\mathrm{~g})}+\mathrm{NO}_{(\mathrm{g})}+\mathrm{H}_{2} \mathrm{O}_{(\mathrm{l})}
\end{aligned}
$$

Sementara itu, penambahan $\mathrm{H}_{2} \mathrm{SO}_{4}$ dan $\mathrm{H}_{2} \mathrm{O}_{2}$ berfungsi untuk membantu proses destruksi yang dilakukan oleh $\mathrm{HNO}_{3}$ agar senyawa-senyawa organik sampel dapat terdekomposisi secara sempurna.

Penentuan zat pengoksidasi terbaik dilakukan dengan mencampurkan masing- masing sampel permen A, B, C, D, dan E. Selanjutnya sampel ditambahkan dengan zat pengoksidasi berupa $\mathrm{HNO}_{3}$ sebanyak 30 $\mathrm{mL}, \mathrm{HNO}_{3} / \mathrm{H}_{2} \mathrm{SO}_{4}(22,5 \mathrm{~mL} / 7,5 \mathrm{~mL})$ dan $\mathrm{HNO}_{3} / \mathrm{H}_{2} \mathrm{SO}_{4} / \mathrm{H}_{2} \mathrm{O}_{2}(20 \mathrm{~mL} / 6,7 \mathrm{~mL} / 3,3$ $\mathrm{mL})$.

Data yang diperoleh kemudian dianalisis dengan one way anova menggunakan uji $\mathrm{F}$ pada taraf signifikansi sebesar $95 \%$. Berdasarkan hasil uji F, diperoleh $\mathrm{F}$ tabel dan $\mathrm{F}$ hitung masingmasing sebesar 5,14 dan 73,961. Artinya $F$ hitung > F tabel. Dengan demikian, maka dapat disimpulkan bahwa terdapat pengaruh yang signifikan antara jenis zat pengoksidasi terhadap perolehan kadar logam tembaga yang dihasilkan. Berikut adalah grafik yang menunjukkan perbedaan pengaruh ketiga jenis zat pengoksidasi terhadap perolehan kadar logam tembaga yang digunakan dalam analisis permen.

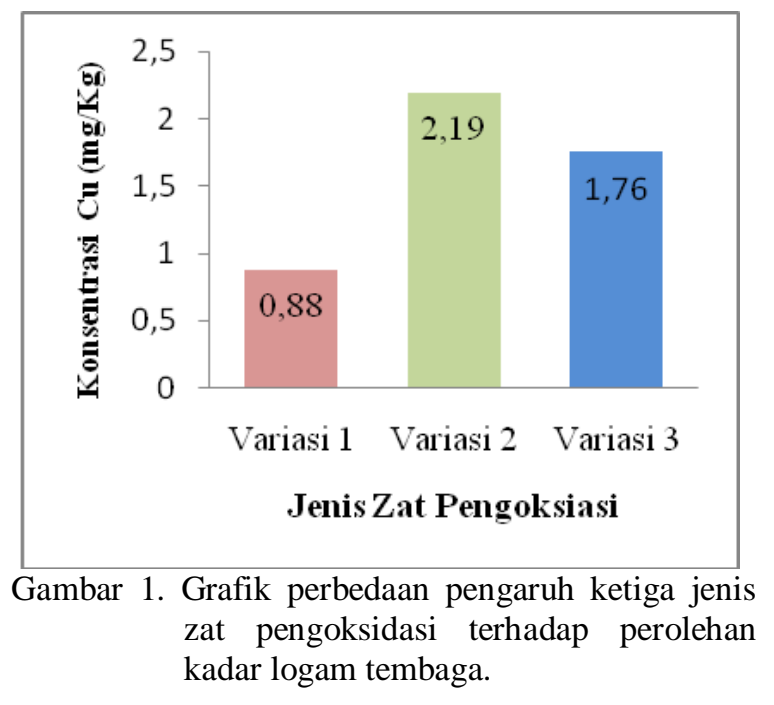

Ket:

Variasi $\mathrm{I}=\mathrm{HNO}_{3}(30 \mathrm{~mL})$

Variasi II $=\mathrm{HNO}_{3} / \mathrm{H}_{2} \mathrm{SO}_{4} 3: 1(22,5 \mathrm{ml} / 7,5 \mathrm{~mL})$

Variasi III $=\mathrm{HNO}_{3} / \mathrm{H}_{2} \mathrm{SO}_{4} / \mathrm{H}_{2} \mathrm{O}_{2} 6: 2: 1(20 \mathrm{~mL} / 6,7 \mathrm{~mL} / 3,3 \mathrm{~mL})$

Penggunaan asam tunggal seperti asam nitrat dalam destruksi dapat dilakukan. Hal itu terjadi karena asam nitrat merupakan asam pengoksidasi yang mengandung ion nitrat yaitu suatu oksidator 
sangat kuat sehingga dapat dengan mudah melepaskan ion hidrogen yang dimilikinya.

Penambahan asam sulfat dalam larutan ini berfungsi sebagai oksidator kuat dimana asam ini akan bekerja dengan baik bila larutan asamnya pekat dan dalam lingkungan yang panas. Penggunaan kombinasi asam sebagai agen digesti lebih menguntungkan jika dibandingkan dengan asam tunggal. Kombinasi asam akan memberikan kekuatan asam yang lebih baik khususnya dalam melarutkan logam-logam yang terdapat dalam sampel organik dan mendegradasi sampel organik.

penambahan asam peroksida pada variasi ketiga tidak memberikan kekuatan asam yang jauh lebih besar dibandingkan dengan zat pendestruksi pada variasi kedua. Hal ini dapat ditinjau juga berdasarkan perbandingan kompoisis volume yang digunakan. Komposisi volume zat pendestruksi pada variasi ketiga $\left(\mathrm{HNO}_{3} / \mathrm{H}_{2} \mathrm{SO}_{4} / \mathrm{H}_{2} \mathrm{O}_{2}\right)$ yaitu $20 \mathrm{~mL} / 6,7 \mathrm{~mL} /$ $3,3 \mathrm{~mL}$. Sementara itu, komposisi pada variasi kedua, $\mathrm{HNO}_{3} / \mathrm{H}_{2} \mathrm{SO}_{4}$ yaitu $22,5 \mathrm{~mL} /$ 7,5 mL. Dengan demikian, jumlah asam peroksida yang digunakan pada variasi ketiga hanya sebesar 3,3 mL. Jumlah penambahan asam peroksida ini tidak terlalu besar dibandingkan dengan zat pengoksidasi $\mathrm{HNO}_{3}$ dan $\mathrm{H}_{2} \mathrm{SO}_{4}$ sehingga tidak memberikan hasil yang jauh lebih baik ketika menggunakan campuran zat pengoksidasi $\mathrm{HNO}_{3}$ dan $\mathrm{H}_{2} \mathrm{SO}_{4}$ (3:1). Namun, jika dibandingkan dengan penggunaan asam tunggal, maka penggunaan zat pengoksidasi $\mathrm{HNO}_{3} / \mathrm{H}_{2} \mathrm{SO}_{4} / \mathrm{H}_{2} \mathrm{O}_{2}$ jauh lebih baik.

Hasil analisis kadar logam tembaga pada permen menggunakan zat pengoksidasi $\mathrm{HNO}_{3} / \mathrm{H}_{2} \mathrm{SO}_{4}$ (3:1) disajikan pada Tabel 2.

Peraturan pemerintah mengenai kadar logam tembaga yang diperbolehkan untuk dikonsumsi telah diatur melalui SNI (Satuan Standar Nasional) yaitu sebesar 2,0 $\mathrm{mg} / \mathrm{kg}$. Dari hasil analisis yang dilakukan diketahui bahwa permen yang dijual di Kota Malang berada dalam ambang batas aman sehingga layak untuk dikonsumsi.

Tabel 2. Kadar logam tembaga pada permen

\begin{tabular}{|c|c|}
\hline Jenis permen & $\begin{array}{c}\text { Kadar rata-rata logam } \\
\text { tembaga }(\mathrm{mg} / \mathrm{Kg})\end{array}$ \\
\hline $\mathrm{A}$ & $1,72 \pm 0,072$ \\
\hline $\mathrm{B}$ & $1,69 \pm 0,0322$ \\
\hline $\mathrm{C}$ & $1,57 \pm 0,02$ \\
\hline $\mathrm{D}$ & $1,71 \pm 0,108$ \\
\hline $\mathrm{E}$ & $1,69 \pm 0,04$ \\
\hline
\end{tabular}

\section{KESIMPULAN}

Zat pengoksidasi terbaik logam tembaga pada sampel permen dengan destruksi basah adalah larutan $\mathrm{HNO}_{3} / \mathrm{H}_{2} \mathrm{SO}_{4}$ (3:1).

Kadar logam tembaga pada permen merek A, B, C, D dan E menggunakan zat pengoksidasi $\mathrm{HNO}_{3} / \mathrm{H}_{2} \mathrm{SO}_{4}$ dengan perbandingan volume $22,5 \mathrm{~mL} / 7,5 \mathrm{~mL}$ sebesar $1,72 \mathrm{mg} / \mathrm{Kg} ; 1,69 \mathrm{mg} / \mathrm{Kg} ; 1,57$ $\mathrm{mg} / \mathrm{Kg} ; 1,71 \mathrm{mg} / \mathrm{Kg}$; dan $1,69 \mathrm{mg} / \mathrm{Kg}$.

\section{DAFTAR PUSTAKA}

Annisa, D. 2012. Penentuan Suhu dan Waktu Terbaik Determinasi Kadar Logam Tembaga dalam Gula Pasir Dengan Metode Microwave Digestion Menggunakan Spektrofotometri Serapan Atom. Skripsi Tidak Diterbitkan. Malang: Jurusan Kimia Fakultas Saintek UIN Maliki Malang.

Darmono. 1995. Logam Dalam Sistem Biologi Makhluk Hidup. Jakarta: Universitas Indonesia Press.

Duran, A.; Tuzen, M.; dan Soylak, M. 2009. Trace Metal Contents In Chewing Gums And Candies Marketed In Turkey. Journal of Environment Monit Assa. 
Ki-Cheol, K.; Yong-Bae, P.; Myung-Jin, L; Jung-Beom, K.; Jeng-Weon, H.; Dae-Hwan, K.; Jung-Bok, L.; dan Jong-Chan, K. 2008. Levels of Heavy Metals In Candy Packages And Candies Likely to be Consumed by Small Children. Food Reaseach International, 41: 411418.

Kristianingrum, S. 2012. Kajian Berbagai Proses Destruksi Sampel Dan Efeknya. Laporan Hasil Prosiding Seminar. Yogyakarta: Universitas Negeri Yogyakarta.

Ochu, J.O.; Uzairu, A.; Kagbu. J.A.; Gimba, C.E.; dan Okunola, O.J.
2012. Evaluation Of Some Heavy Metals in Imported Chocolate and Candies Sold In Nigeria. Journal of Food Research Vol. 1, No.3. Canadian Center of Science and Education.

Prihatiningsih, W. K. 2007. Penetapan Kadar Tembaga $(\mathrm{Cu})$ Pada Sampel Air Dengan Metode Spektrofotometri di Laboratorium PDAM Tirtanadi Medan. Tugas Akhir. Medan: Fakultas Farmasi USU. 